(c) American Dairy Science Association, 2005.

\title{
Influence of Thermal Processing Conditions on Flavor Stability in Fluid Milk: Benzaldehyde
}

\author{
R. V. Potineni and D. G. Peterson \\ Department of Food Science, \\ The Pennsylvania State University, University Park 16802
}

\begin{abstract}
Flavor loss in dairy products has been associated with enzymatic degradation by xanthine oxidase. This study was conducted to investigate the influence of milk thermal processing conditions (or xanthine oxidase inactivation) on benzaldehyde stability. Benzaldehyde was added to whole milk which had been thermally processed at 4 levels: (1) none or raw, (2) high temperature, short time (HTST) pasteurization, (3) HTST pasteurization, additionally heated to $100^{\circ} \mathrm{C}(\mathrm{PAH})$, and (4) UHT sterilized. Additionally, PAH and UHT milk samples containing benzaldehyde (with and without ferrous sulfate) were spiked with xanthine oxidase. Azide was added as an antimicrobial agent (one additional pasteurized sample without) and the microbial load (total plate count) was determined on $\mathrm{d} 0,2$, and 6 . The concentration of benzaldehyde and benzoic acid in all milk samples were determined at d 0,1,2, 4, and 6 (stored at $5^{\circ} \mathrm{C}$ ) by gas chromatography/mass spectrometry in selective ion monitory mode. Over the 6-d storage period, more than $80 \%$ of the benzaldehyde content was converted (oxidized) to benzoic acid in raw and pasteurized milk, whereas no change in the benzaldehyde concentration was found in PAH or UHT milk samples. Furthermore, the addition of xanthine oxidase or xanthine oxidase plus ferrous sulfate to PAH or UHT milk samples did not result in benzaldehyde degradation over the storage period.
\end{abstract}

(Key words: thermal processing, benzaldehyde, dairy, flavor degradation)

Abbreviation key: GCMS = gas chromatography/ mass spectrometry, PAH = pasteurized milk additionally heated to $100^{\circ} \mathrm{C}$.

\section{INTRODUCTION}

Effective use of flavoring materials is an important parameter for the manufacture of flavor-enriched food

Received August 24, 2004.

Accepted September 24, 2004.

Corresponding author: D. G. Peterson; e-mail: dgp10@psu.edu. products. Ideally, the flavor component of a food product should remain stable from the time of manufacture throughout the anticipated product shelf life. However, numerous product traits (i.e., matrix composition or processing conditions) can influence product flavor stability. Consequently, defining key modes of flavor loss or degradation would provide useful information for the food industry, such as the dairy industry, which commonly produces flavor-enriched food products (e.g., ice cream, flavored milks, yogurt).

Flavor degradation in dairy products has been previously linked to enzymatic reactions (Baumgartner and Neukom, 1972; Chevalier et al., 1972; Allen and Wrieden, 1982a; Jeon, 1993; Anklam et al., 1997; Kempe and Kohnen, 1999; Ostdal et al., 2000; Gassenmeier, 2003). Recently, Anklam et al. (1997) and Gassenmeier $(2003,2004)$ studied the degradation of vanillin to vanillic acid in select dairy products during storage and associated this degradation reaction to oxidative activity of the intrinsic milk enzyme xanthine oxidase. Gassenmeier (2003, 2004) suggested that lipid oxidation derived off-flavor compound could be generated via a coupled chemical reaction during the enzymatic oxidation of vanillin.

Flavor-protein interactions have been widely investigated with regard to flavor loss in dairy products (Damodaran and Kinsella, 1980; O'Neill and Kinsella, 1987; Hansen and Heinis, 1992; Guichard and Langourieux, 2000; Fabre et al., 2002). Hansen and Brooker (1996) and Hansen and Heinis (1992) reported that the perceived aroma intensity of specific flavor compounds (i.e., vanillin, benzaldehyde, citral, and limonene) was reduced in the presence of milk proteins in aqueous solutions. For example, they indicated that the perceived flavor intensity of benzaldehyde was inversely related to the concentration of whey protein, whereas no significant difference in flavor intensity was observed with respect to casein. The flavor binding properties of whey protein have been primarily characterized as reversible hydrophobic binding effects of $\beta$-lactoglobulin (Langourieux and Crouzet, 1995; Jouenne and Crouzet, 1996; Andriot et al., 1999; Guichard and Langourieux, 2000; Jung et al., 2002). 
The current study was based on empirical findings reported by a Penn State alumnus (Stuart Patton) who observed that Stuzipan ice cream [Penn State Creamery; a marzipan flavored product, (Baumracker, 2000; S. Patton, personal communication, 2003)] had a low overall flavor impact. This suggested that key character impact aroma compounds (i.e., benzaldehyde) might be unstable in dairy products. Because ice cream has a relatively high hydrophobic matrix, flavor losses due to hydrophobic protein interactions between benzaldehyde and $\beta$-lactoglobulin would not be anticipated to have a significant impact on the flavor intensity of a full-fat ice cream. However, based on previous studies suggesting the oxidation of vanillin to vanillic acid in dairy-based products via intrinsic oxidative enzymes (i.e., xanthine oxidase), it was considered that benzaldehyde might likewise be degraded to benzoic acid by similar pathways. The objectives of this study were (1) to analytically monitor the change in concentration of a benzaldehyde-spiked milk sample and the concomitant formation of benzoic acid over time, and (2) determine if the heat treatment influenced benzaldehyde stability (associated with enzymatic inactivation).

\section{MATERIALS AND METHODS}

Benzaldehyde, benzoic acid, and hydrochloric acid (12 $N$ ) were purchased from Aldrich (Sigma Aldrich, Milwaukee, WI). Methanol was from Fisher Scientific (Fairlawn, NJ). Hexane and acetone were from EMD Chemicals (Gibbstown, NJ). Methyl hexanoate was purchased from TCI America (Portland, OR). Fresh milk and pasteurized milk were purchased from The Pennsylvania State University creamery (University Park, PA), and UHT milk was from Parmalat USA (Wallington, NJ). 3M Petrifilm for aerobic count plates was from 3M Company (St. Paul, MN). Bovine xanthine oxidase (10 U) was from EMD Biosciences (San Diego, CA). Ferrous sulfate was from J. T. Baker (Phillipsburg, NJ).

\section{Sample Preparation}

Benzaldehyde (110 mg/L) was added to 4 thermally processed whole milk samples. The different treatments included 1) raw (no treatment), 2) HTST pasteurization, 3) HTST pasteurization followed by further heating to $100^{\circ} \mathrm{C}(\mathbf{P A H})$, and 4) UHT treatment. An additional UHT milk sample with $40 \mathrm{mU} / \mathrm{mL}$ xanthine oxidase activity was analyzed. Benzaldehyde was added to all milk samples at or below $5^{\circ} \mathrm{C}$. Sodium azide $(200 \mathrm{mg} / \mathrm{L})$ was added as an antimicrobial agent to each sample. An additional pasteurized milk sample without sodium azide was also concurrently analyzed. All sam- ples were stored at $5^{\circ} \mathrm{C}$ in the dark over a 6 -d period in 200-mL glass jars with Teflon closures and analyzed for the concentration of benzaldehyde and benzoic acids on d $0,1,2,4$, and 6 .

\section{Microbial Analyses}

The 3M Petrifilm aerobic count plate was used to enumerate total aerobic microbial plate count. For counts in aerobic count plates, $1-\mathrm{mL}$ aliquots of $1: 10$, $1: 100$, and $1: 1000$ dilutions of milk samples were plated using phosphate buffer, $\mathrm{KH}_{2} \mathrm{PO}_{4}(0.0425 \mathrm{~g} / \mathrm{L}$, adjusted to $\mathrm{pH}$ 7.2). All plates were incubated at $32^{\circ} \mathrm{C} \pm 2{ }^{\circ} \mathrm{C}$ for $48 \mathrm{~h}$. Red colonies on countable plates were enumerated regardless of colony size. Microbial analysis was conducted on $\mathrm{d} 0,2$, and 6 .

\section{Solvent Extraction}

Milk samples $(20 \pm 0.1 \mathrm{~g})$ were acidified to $\mathrm{pH} 1.5$ using hydrochloric acid $(1 N)$, in 50 -mL centrifuge tubes (Nalgene International, Rochester, NY). This step was followed by a 2 -stage extraction process. During the first stage, $8 \mathrm{~g}$ of hexane:acetone (10:1) solvent mixture containing $\mathrm{N}$-caproic acid methyl ester (as internal standard; $100 \mathrm{mg} / \mathrm{L}$ ) was added to the acidified milk samples. Samples were then centrifuged $(7025 \times g ; 12$ min) in a Beckman GPR Centrifuge (Palo Alto, CA) and the supernatant solvent mixture was collected. Moisture was removed from the solvent mixture ( $5 \mathrm{~g}$ ) using $1 \mathrm{~g}$ of anhydrous $\mathrm{Na}_{2} \mathrm{SO}_{4}$.

Second stage solvent extraction included extraction of flavor compounds into $1 \mathrm{~g}$ of methanol from $4 \mathrm{~g}$ of hexane/acetone mixture obtained from the previous step. The methanol extract was then directly analyzed by gas chromatography/mass spectrometry (GCMS).

\section{Gas Chromatography/Mass Spectrometry}

An Agilent 6890 GC (Agilent Technologies, Palo Alto, CA) equipped with a split/splitless injector coupled with a mass selective detector HP 5972A (Hewlett-Packard, Palo Alto, CA), CTC A2000S liquid auto sampler (Leap Tec., Carrboro, NC) and a fused-silica capillary column (DB-FFAP, $30 \mathrm{~m}, 0.32 \mathrm{~mm}$ i.d., $0.32 \mu \mathrm{m}$ film thickness, Agilent Technologies, CA) was used for analysis. The GC operating conditions were as follows: $1 \mu \mathrm{L}$ of sample was injected in splitless mode; sample tray maintained at $5^{\circ} \mathrm{C}$; inlet temperature was $200^{\circ} \mathrm{C}$, oven program was $40^{\circ} \mathrm{C}$ for $2 \mathrm{~min}$, then increased at $10^{\circ} \mathrm{C} / \mathrm{min}$ to $230^{\circ} \mathrm{C}$ and held for $3 \mathrm{~min}$; constant flow rate of $0.7 \mathrm{~mL} / \mathrm{min}$ $\left(\mathrm{H}_{2}\right)$. The MS operating conditions were as follows: capillary direct interface temperature was $260^{\circ} \mathrm{C}$; for SCAN mode the mass range was 35 to $200 \mathrm{amu}$ (atomic 


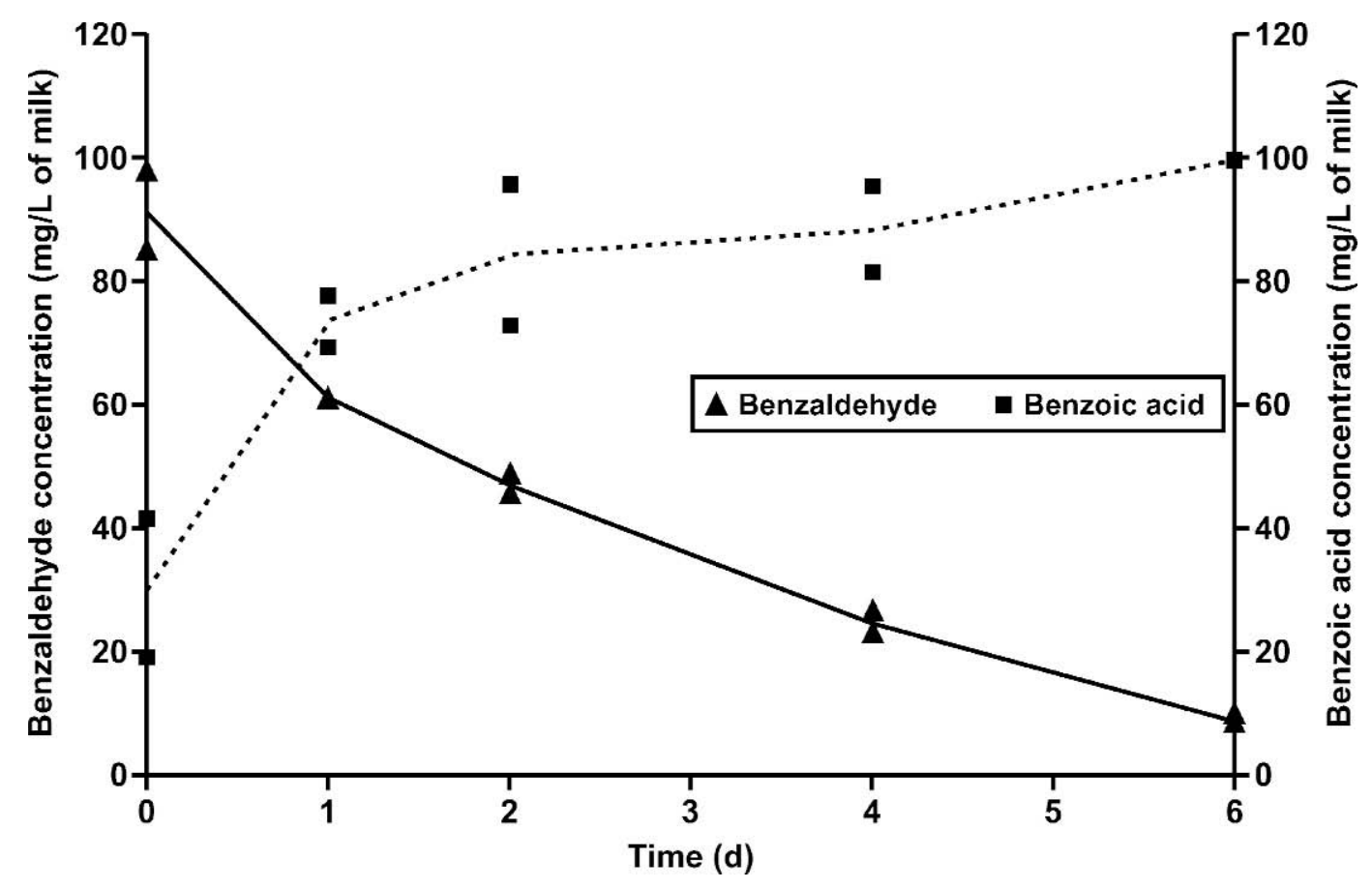

Figure 1. Degradation of benzaldehyde and formation of benzoic acid in raw milk. Triangles indicate benzaldehyde concentration (left axis); squares indicate benzoic acid concentration (right axis).

mass units); for selective ion monitory mode, specific ions monitored were 106 for benzaldehyde, 99 for methyl hexanoate (internal standard), and 122 for benzoic acid.

\section{Quantitative/Qualitative Analyses of Target Compounds}

Qualitative analyses as well as quantitative analyses were done using GCMS, in scan (GCMS-SCAN) and selective ion monitory (GCMS-SIM) modes, respectively. Peak areas obtained from MS data were used to determine the concentrations using a standard curve based on benzaldehyde $\left(\mathrm{r}^{2}=0.99\right)$ as well as benzoic acid $\left(r^{2}=0.98\right)$ added to UHT milk and extracted as described in this section. The standards were run in duplicates: $0,35,60,85,110 \mathrm{mg}$ of benzaldehyde and benzoic acid per liter of milk.

\section{RESULTS AND DISCUSSION}

The stability of benzaldehyde (or its degradation to benzoic acid) in fluid milk samples which were processed at 4 different levels of thermal treatment over a 6-d period of storage at $5^{\circ} \mathrm{C}$ are shown in Figures 1 to 4 . The thermal treatment level of the milk sample had a definite effect on the stability of benzaldehyde. For the raw milk and pasteurized milk samples (con- taining azide), more than $90 \%$ of the benzaldehyde was converted (oxidized) to benzoic acid over the 6-d period (Figures 1 and 2, respectively). On the contrary, for the PAH (which was additionally heated to $100^{\circ} \mathrm{C}$ ) and UHT milk samples, no degradation of benzaldehyde to benzoic acid over the 6-d period was apparent (Figures 3 and 4, respectively). Furthermore, autoxidation lipid degradation products, such as hexanal, were not identified in all the above samples (data not shown), suggesting an alternative degradation pathway.

The microbial analysis of the milk samples (Table 1) indicated that addition of azide inhibited microbial growth, whereas for the pasteurized milk sample containing no azide, microbial growth was evident during storage (as anticipated). Comparison of benzaldehyde stability for the pasteurized milk sample with and without azide (Figure 2), showed a lower rate of benzoic formation for the sample without azide. The large viable microbial load in the milk sample without azide may have resulted in a reduced oxygen concentration that retarded the oxidation of benzaldehyde.

The observed improved stability of benzaldehyde in fluid milk samples processed under more severe thermal conditions than HTST pasteurization would be anticipated if enzymatic reactions were responsible for the oxidative conversion to benzoic acid; a reaction that has been previously suggested for the observed conversion of vanillin to vanillic acid in select dairy products. 


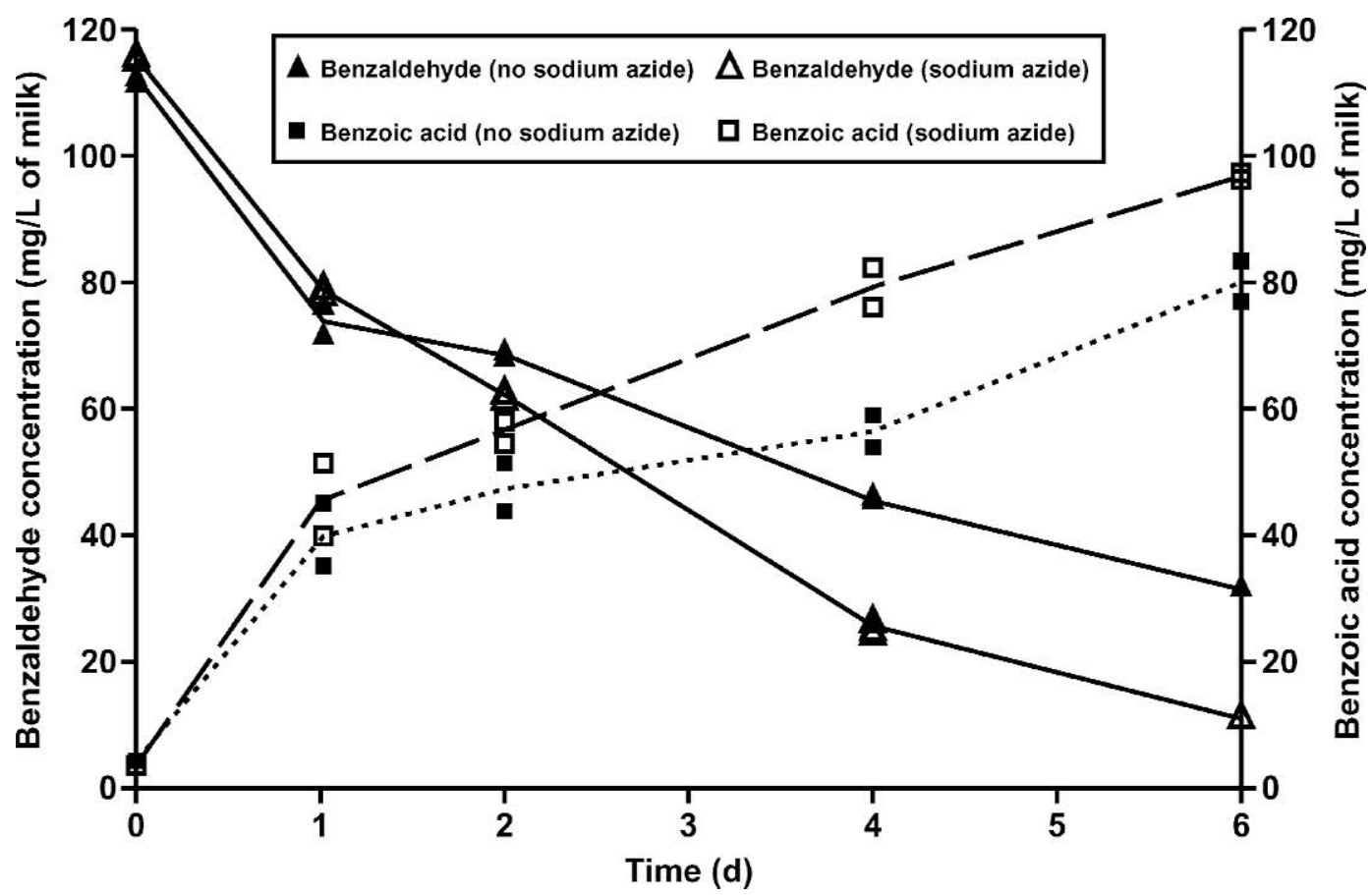

Figure 2. Degradation of benzaldehyde and formation of benzoic acid in pasteurized milk (with and without azide). Triangles indicate benzaldehyde concentration (left axis); squares indicate benzoic acid concentration (right axis); solid shapes indicate milk samples without sodium azide, and open shapes represent milk samples with added sodium azide.

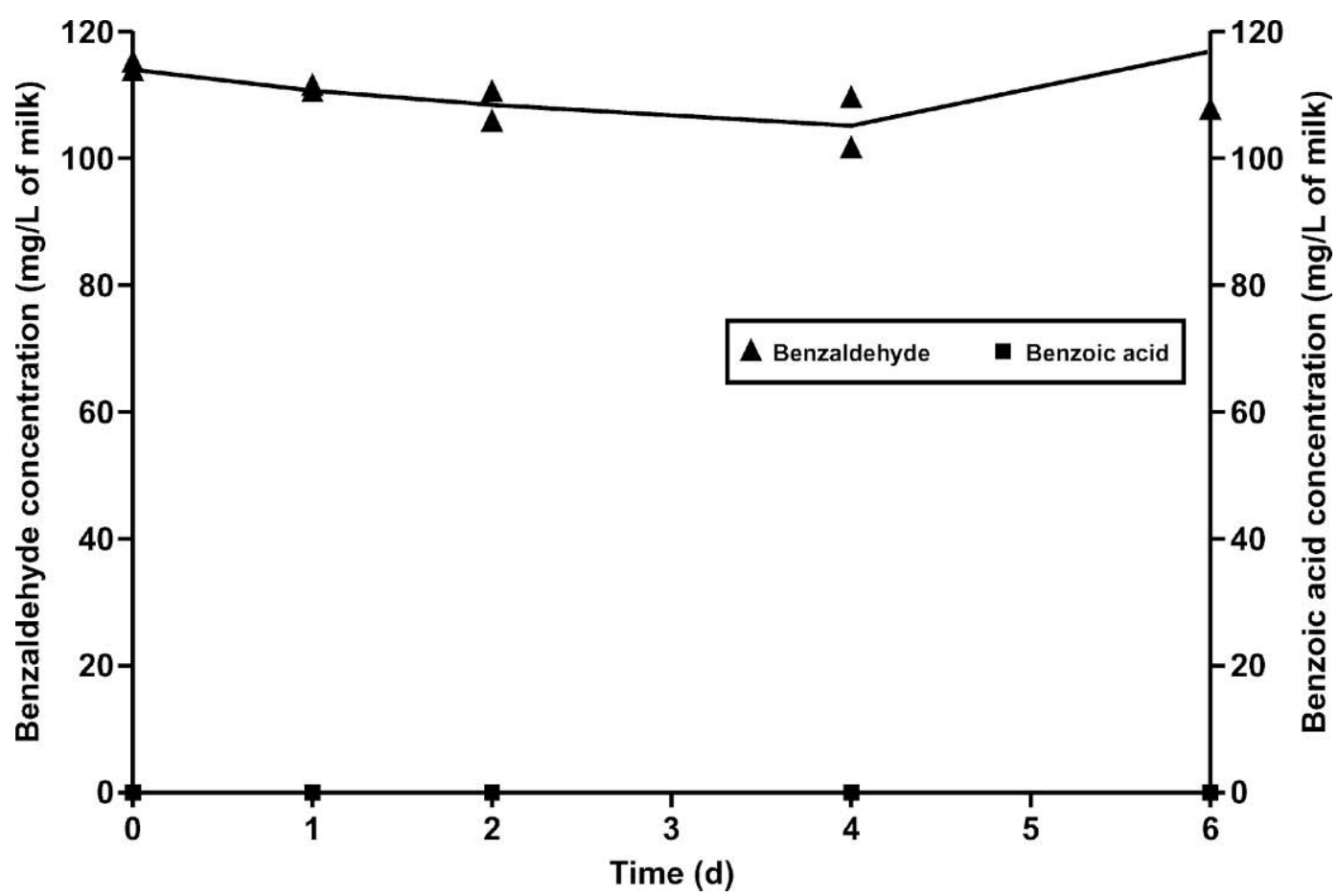

Figure 3. Degradation of benzaldehyde and formation of benzoic acid in pasteurized milk heated to $100^{\circ} \mathrm{C}$. Triangles indicate benzaldehyde concentration (left axis); squares indicate benzoic acid concentration (right axis). No benzoic acid formation occurred. 


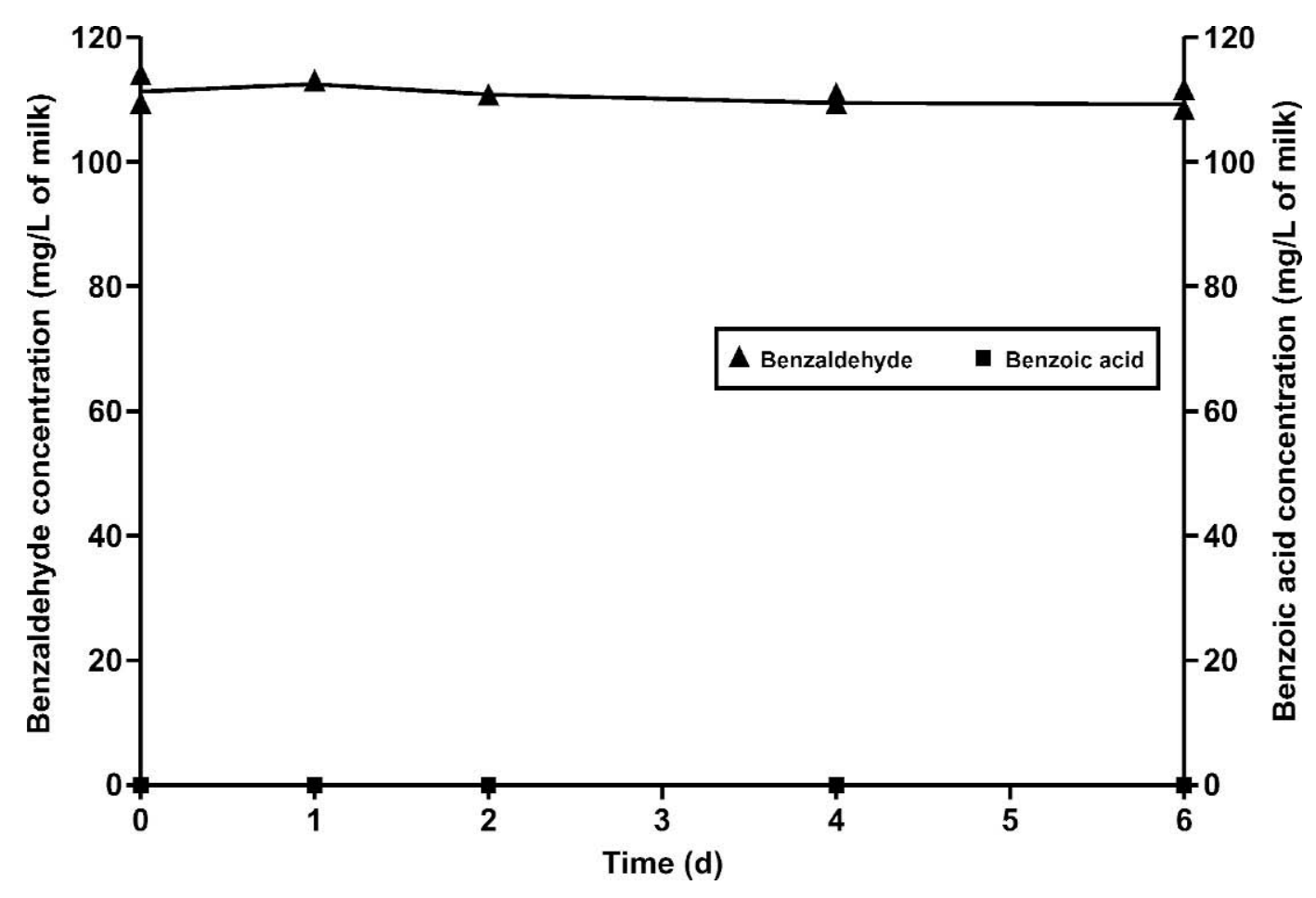

Figure 4. Degradation of benzaldehyde and formation of benzoic acid in UHT milk. Triangles indicate benzaldehyde concentration (left axis); squares indicate benzoic acid concentration (right axis). No benzoic acid formation occurred.

Anklam et al. (1997), Baumgartner and Neukom (1972), and Gassenmeier $(2003,2004)$ reported the degradation of vanillin to vanillic acid in dairy products and suggested xanthine oxidase as the oxidative pathway. Based on the thermal inactivation of xanthine oxidase ( $7 \mathrm{~min}$ at $73^{\circ} \mathrm{C}$ or $\sim 50 \mathrm{~s}$ at $80^{\circ} \mathrm{C}$; (Walstra et al., 1999), both the raw and pasteurized milk samples would be expected to have xanthine oxidase activity, whereas the $\mathrm{PAH}$ and UHT milks would not. In the current study, however, addition of $40 \mathrm{mU} / \mathrm{mL}$ xanthine oxidase activity in UHT milk, as previously reported in pasteurized milk (Cerbulis and Ferrell, 1977), was not found to degrade benzaldehyde to benzoic acid at $5^{\circ} \mathrm{C}$ over a 6-d period (data not shown). Possibly, the enzymatic degradation of benzaldehyde via xanthine oxidase is dependent on other matrix parameters such as the availability of transition metals (Allen and Wrieden, 1982a). Milk proteins are known to have relatively strong antioxidant properties, presumably due to their protein-metal chelating activity (Allen and Wrieden, 1982b; Cervato et al., 1999). Perhaps, the metal binding properties of milk proteins increased with higher protein denaturation and therefore may have correlated to the extent of thermal treatment. To determine if the thermal treatment had an affect on metal availability, PAH milk samples containing xanthine oxidase $(40 \mathrm{mU} /$ $\mathrm{mL})$ spiked with ferrous sulfate $(100 \mathrm{mg} / \mathrm{L})$ were analyzed over a period of $6 \mathrm{~d}$. Results showed no formation of benzoic acid during this time. Moreover, UHT milk samples containing xanthine oxidase $(40 \mathrm{mU} / \mathrm{mL})$ when

Table 1. Microbial count (total plate count) ${ }^{1}$ for different thermally treated milks at d 0,2 , and 6 .

\begin{tabular}{llllll}
\hline & \multicolumn{5}{c}{ Thermal treatment $^{2}$} \\
\cline { 2 - 6 } Time & $\begin{array}{l}\text { Raw milk } \\
\text { with azide }\end{array}$ & $\begin{array}{l}\text { Pasteurized } \\
\text { without azide }\end{array}$ & $\begin{array}{l}\text { Pasteurizd } \\
\text { with azide }\end{array}$ & $\begin{array}{l}\text { PAH }^{3} \\
\text { with azide }\end{array}$ & $\begin{array}{l}\text { UHT } \\
\text { with azide }\end{array}$ \\
\hline Day 0 & 3.16 & 2.72 & $2.20^{\text {est }}$ & ND & ND \\
Day 2 & $2.36^{\text {est }}$ & 2.66 & ND & ND & ND \\
Day 6 & $1.38^{\text {est }}$ & TNTC & ND & ND & ND \\
\hline
\end{tabular}

${ }^{1}$ est $=$ Estimated, ND = not detected, TNTC = too numerous to count.

${ }^{2}$ Treatments with azide included $200 \mathrm{mg} / \mathrm{L}$ of sodium azide as an antimicrobial agent.

${ }^{3} \mathrm{PAH}=$ HTST Pasteurized milk additionally heated to $100^{\circ} \mathrm{C}$. 
spiked with ferrous sulfate $(100 \mathrm{mg} / \mathrm{L})$ similarly showed no changes in benzaldehyde concentration, although it should be noted that the 'available' iron might be negligible. This implied that xanthine oxidase might not be the direct mode of benzaldehyde oxidation to benzoic acid in milk. Possibly other pro-oxidative enzymes (singularly or in combination) or chemical pathways may responsible for benzaldehyde instability in pasteurized milk products.

Historically, a major drawback of high temperature treatment of milk products (i.e., UHT) is the simultaneous generation of thermally generated flavor/off-flavor compounds that ultimately result in the development of negative product traits such as cooked flavor (Beck and Hicks, 1980; Perkins and Deeth, 2001). Recently, Colahan-Sederstrom and Peterson (2004) found the addition of a flavonoid, such as epicatechin, to milk before UHT processing inhibited the formation of thermally generated "cooked" aroma compounds (or had similar flavor attributes to pasteurized milk).

\section{CONCLUSIONS}

Fluid milk processed under more severe thermal conditions than HTST processing resulted in improved stability of benzaldehyde. However, the addition of xanthine oxidase (with and without ferrous sulfate) to UHT or PAH milk did not result in the benzaldehyde degradation that was observed in the pasteurized or raw milk samples. Although stability of benzaldehyde was influenced by heat treatment, the presence of xanthine oxidase activity was not sufficient to degrade benzaldehyde in milk products, as has been previously suggested with vanillin degradation in milk products.

\section{REFERENCES}

Allen, J. C., and W. L. Wrieden. 1982a. Influence of milk proteins on lipid oxidation in aqueous emulsion. II. Lactoperoxidase, lactoferrin, superoxide dismutase and xanthine oxidase. J. Dairy Res. 49:249-263.

Allen, J. C., and W. L. Wrieden. 1982b. Influence of milk proteins on lipid oxidation in aqueous emulsion. I. Casein, whey protein, and $\alpha$-lactalbumin. J. Dairy Res. 49:239-248.

Andriot, I., I. Marin, G. Feron, P. Relkin, and E. Guichard. 1999. Interactions between $\beta$-lactoglobulin and benzaldehyde studied by static headspace and high performance liquid chromatography in different conditions. Lait 79:577-586.

Anklam, E., S. Gaglione, and A. Muller. 1997. Oxidation behaviour of vanillin in dairy products. Food Chem. 60:43-51.

Baumgartner, J., and H. Neukom. 1972. Enzymatische Oxidation von Vanillin. Chimia (Aarau) 26:366-368.

Baumracker, C. 2000. New ice cream flavor to honor Penn State dairy pioneer and scholar. Penn State News. Online. Available: http:// aginfo.psu.edu/News/august00/patton.html. Accessed Oct. 5, 2004 .
Beck, R., and C. Hicks. 1980. Could UHT milk change the U.S. dairy industry? Hoard's Dairyman. 125:437, 480.

Cerbulis, J., and H. M. J. Ferrell. 1977. Xanthine oxidase activity in dairy products. J. Dairy Sci. 60:170-184.

Cervato, G., R. Cazzola, and B. Cestaro. 1999. Studies on the antioxidant activity of milk casein. Int. J. Food Sci. Nutr. 50:291-296.

Chevalier, M., Y. Prat, and P. Navellier. 1972. Caracterisation par chromatographic en couche mince des constituants aromatiques de la vanille dans les glaces et cremes glacees. Ann. Fals. Exp. Chim. 697:12-16.

Colahan-Sederstrom, P. M., and D. G. Peterson. 2004. Inhibition of key aroma compound generated during ultra-high temperature processing of bovine milk via epicatechin addition. J. Agric. Food Chem.

Damodaran, S., and J. E. Kinsella. 1980. Flavor protein interactions: Binding of carbonyls to bovine serum albumin: Thermodynamic and conformational effects. J. Agric. Food Chem. 28:567-571.

Fabre, M., V. Aubry, and E. Guichard. 2002. Comparison of different methods: Static and dynamic headspace and solid-phase microextraction for the measurement of interactions between milk proteins and flavor compounds with an application to emulsions. J. Agric. Food Chem. 50:1497-1501.

Gassenmeier, K. 2003. Vanillin and xanthineoxidase-Key factors for the generation of a cardboard off-note in vanilla ice cream. Lebensm. Wiss. U.-. Technol. 36:99-103.

Gassenmeier, K. 2004. Interactions of selected flavor compounds with selected dairy products. Pages 259-266 in Handbook of Flavor Characterization: Sensory analysis, chemistry, and physiology. K. D. Deibler and J. Delwiche, ed. Marcel Dekker, New York, NY.

Guichard, E., and S. Langourieux. 2000. Interactions between [beta]lactoglobulin and flavour compounds. Food Chem. 71:301-308.

Hansen, A. P., and D. C. Brooker. 1996. Flavor Interaction with casein and whey protein. Pages 75-89 in Flavor-Food Interactions. Vol. 633. R. J. McGorrin and J. V. Leland, ed. American Chemical Society, Washington, DC.

Hansen, A. P., and J. J. Heinis. 1992. Benzaldehyde, citral, and dlimonene flavor perception in the presence of casein and whey proteins. J. Dairy Sci. 72:1211-1215.

Jeon, I. J. 1993. Undesirable flavors in dairy products. Pages 139 167 in Food taints and off-flavors. M. J. Saxby, ed. Chapman and Hall, London, UK.

Jouenne, E., and J. Crouzet. 1996. Interactions of aroma compounds with $\beta$-lactoglobulin. Pages 425-429 in Flavour Science, Recent Developments: Proceedings of the 8th Weurman symposium. A. J. Taylor and D. S. Mottram, ed. The Royal Society of Chemistry, Cambridge, UK.

Jung, D. M., J. S. de Ropp, and S. E. Ebeler. 2002. Application of pulsed field gradient NMR techniques for investigating binding of flavor compounds to micromolecules. J. Agric. Food Chem. 50:4262-4269.

Kempe, K., and M. Kohnen. 1999. Deterioration of natural vanilla flavours in dairy products during processing. Adv. Food Sci. $21: 48-53$.

Langourieux, S., and J. Crouzet. 1995. Study of aroma compoundnatural polymer interactions by dynamic coupled column liquid chromatography. J. Chromatogr. A 707:181-187.

O'Neill, T., and J. E. Kinsella. 1987. Flavor protein interactions: Characteristics of 2-nonanone binding to isolated soy protein fractions. J. Food Sci. 52:98-101.

Ostdal, H., M. J. Bjerrum, J. A. Pedersen, and H. J. Andersen. 2000. Lactoperoxidase-induced protein oxidation in milk. J. Agric. Food Chem. 48:3939-3944.

Perkins, M., and H. Deeth. 2001. A survey of Australian consumers' attitudes toward UHT milk. Aust. J. Dairy Technol. 56:28-34.

Walstra, P., T. J. Geurts, A. Noomen, A. Jellema, and M. A. J. S. Van Boekel. 1999. Dairy Technology: Principles of Milk Properties and Processes. Marcel Dekker Inc., New York, NY. 